\title{
Investigating the composition of organic aerosol resulting from cyclohexene ozonolysis: low molecular weight and heterogeneous reaction products
}

\author{
J. F. Hamilton ${ }^{1}$, A. C. Lewis ${ }^{1}$, J. C. Reynolds ${ }^{1}$, L. J. Carpenter ${ }^{1}$, and A. Lubben ${ }^{2}$ \\ ${ }^{1}$ Department of Chemistry, University of York, Heslington, York, YO10 5DD, UK \\ ${ }^{2}$ Bruker Daltonics, Banner Lane, Coventry, CV4 9GH, UK \\ Received: 26 April 2006 - Published in Atmos. Chem. Phys. Discuss.: 12 July 2006 \\ Revised: 29 September 2006 - Accepted: 24 October 2006 - Published: 30 October 2006
}

\begin{abstract}
The composition of organic aerosol formed from the gas phase ozonolysis of cyclohexene has been investigated in a smog chamber experiment. Comprehensive gas chromatography with time of flight mass spectrometric detection was used to determine that dicarboxylic acids and corresponding cyclic anhydrides dominated the small gas phase reaction products found in aerosol sampled during the first hour after initial aerosol formation. Structural analysis of larger more polar molecules was performed using liquid chromatography with ion trap tandem mass spectrometry. This indicated that the majority of identified organic mass was in dimer form, built up from combinations of the most abundant small acid molecules, with frequent indication of the inclusion of adipic acid. Trimers and tetramers potentially formed via similar acid combinations were also observed in lower abundances. Tandem mass spectral data indicated dimers with either acid anhydride or ester functionalities as the linkage between monomers. High-resolution mass spectrometry identified the molecular formulae of the most abundant dimer species to be $\mathrm{C}_{10} \mathrm{H}_{16} \mathrm{O}_{6}, \mathrm{C}_{11} \mathrm{H}_{18} \mathrm{O}_{6}$, $\mathrm{C}_{10} \mathrm{H}_{14} \mathrm{O}_{8}$ and $\mathrm{C}_{11} \mathrm{H}_{16} \mathrm{O}_{8}$ and could be used in some cases to reduce uncertainty in exact chemical structure determination by tandem MS.
\end{abstract}

\section{Introduction}

It has recently been established that significant amounts of particulate matter are organic in nature deriving from both primary and secondary sources, where organic material can contribute $20-50 \%$ of the total fine (sub-micron) aerosol mass in continental mid-latitudes (Putaud et al., 2004; Saxena and Hildemann, 1996) and up to $90 \%$ in tropical highly forested areas (Andreae and Crutzen, 1997; Artaxo et al.,

Correspondence to: J. F. Hamilton

(jfh2@york.ac.uk)
1988; Talbot et al., 1988). Volatile organic compounds (VOCs) are emitted to the atmosphere from both biogenic and anthropogenic sources, which within the boundary layer of the troposphere have the ability to react rapidly with $\mathrm{NO}_{\mathrm{x}}$ in the presence of $\mathrm{OH}$ radicals to form ozone and other photochemical by-products. Secondary organic aerosol (SOA) can form in the atmosphere following the photo-oxidation of these gas phase organic species which often result in the formation of lower vapour pressure products. In order to understand and predict the growth and ageing of SOA, and its subsequent radiative and hygroscopicity characteristics, it is necessary to understand both the chemical nature of SOA precursors, and the end products and mechanisms by which SOA is formed.

Partitioning of organic compounds to the aerosol phase and subsequent reactions both on the aerosol surface and within the bulk particle are currently poorly understood. In previous studies of speciation of organics in SOA, the observation of compounds whose vapour pressure should prohibit their incorporation into the aerosol could not be explained (Forstner et al., 1997; Jang and Kamens 2001). More recently however, high molecular weight and hence low volatility, organic species have been found in aerosol formed during smog chamber studies from a range of precursors (Kalberer et al., 2004). It has been suggested that heterogeneous reactions, both on the surface and within the bulk, may aid the incorporation of volatile compounds, producing stable macromolecules or polymers within the aerosol. The nature of this low volatility fraction and its formation reactions are still highly uncertain however.

High molecular weight reaction products have been identified in aged SOA from a wide range of compounds, including 1,3,5-trimethylbenzene, cycloalkenes, $\alpha$-pinene and glyoxal (Bahreini et al., 2005; Gao et al., 2004a; Hastings et al., 2005; Kalberer et al., 2004; Kalberer et al., 2005). Initial evidence provided a size distribution using Laser Desorption Ionisation Mass Spectrometry (LDI-MS) (Kalberer

Published by Copernicus GmbH on behalf of the European Geosciences Union. 
et al., 2004), but this approach was unable to provide detailed structural information. Tolocka et al. (2004) applied liquid chromatography combined with matrix-assisted laser desorption ionisation (MALDI), electrospray ionisation (ESI) and chemical ionisation (CI) mass spectrometry. CI was found to cause decomposition of the parent oligomer, but MALDI and ESI provided similar oligomer distributions. Tandem mass spectrometry using a quadrupole time of flight (Q-TOF) mass spectrometer allowed structural identification of individual compounds including dimers, trimers and tetramers of known gas phase reaction products from the ozonolysis of $\alpha$-pinene. Currently however only a very limited number of VOCs have been tested as precursors and little information on the exact oligomers structures and hence formation mechanisms are available.

Cyclohexene is emitted to the atmosphere from both anthropogenic and natural sources. Reaction of cyclohexene with ozone can occur in dark conditions and is a known night time source of $\mathrm{OH}$ radicals. Although of relatively low individual abundance in the atmosphere it has been studied in the laboratory extensively, since it acts as a simple surrogate for the behaviour of more complex terpenoid species. Limited information is available on the composition of SOA produced from this reaction but a number of recent studies have shown the occurrence of oligomers in aged aerosol (4-6h after start of reaction) (Bahreini et al., 2005; Gao et al., 2004a; Gao et al., 2004b).

This paper describes a detailed analysis of chemicals found within SOA formed during a cyclohexene ozonolysis reaction in the European Photoreactor (EUPHORE) chamber. Three complimentary state of the art analytical techniques were used to identify the composition of cyclohexene SOA including both early generation gas phase reaction products (i.e. the monomer building blocks) and higher molecular weight products, formed from heterogeneous reactions either on the surface or within the bulk of the aerosol. Thermal desorption coupled to comprehensive gas chromatography with time-of-flight mass spectrometry (GCXGC-TOF/MS) has previously been used to identify small molecules in toluene photo-oxidation SOA and has been used in this study (Hamilton et al., 2005). A technique to identify oligomers in SOA using reverse phase liquid chromatography with electrospray ionisation and ion-trap mass spectrometry (LC-ESI-MS/MS) was developed and the results are presented. Empirical formulae were subsequently determined for the major components identified in LC-ESIMS/MS using liquid chromatography coupled to high mass accuracy Time-of-Flight MS (LC-ESI-TOF)

\section{Experimental}

Experiments were carried out at the European Photoreactor (EUPHORE) in Valencia, Spain, which consists of two FEPTeflon hemispheres, each with a volume of approximately
$200 \mathrm{~m}^{3}$. The floor is water-cooled to minimise solar heating and an air purification and drying system provides $\mathrm{NO}_{\mathrm{y}^{-}}$ NMHC-free and dry air while two fans ensure homogenous mixing of the chamber air. The concentrations of cyclohexene and ozone were $600 \mathrm{ppb}$ and $420 \mathrm{ppb}$ respectively, with cyclohexene added in a stepwise manner over the course of the experiment. Excess $i$-propanol $(8 \mathrm{ml})$ was used as an $\mathrm{OH}$ scavenger. No seed aerosol was used and the relative humidity was around $3 \%$. Samples were collected on $47 \mathrm{~mm}$ diameter quartz-fibre filters using a high volume sample pump. Filters were pre-fired at $500^{\circ} \mathrm{C}$ for $12 \mathrm{~h}$ prior to sample collection, and were stored in a sealed vial below $4{ }^{\circ} \mathrm{C}$ until analysis. Samples were collected at approximately $74.4 \mathrm{~L} \mathrm{~min}^{-1}$ for $60 \mathrm{~min}$, with a total sample volume of $4.48 \mathrm{~m}^{3}$. The total mass of aerosol collected onto the filter was $794 \mu \mathrm{g}$ giving a concentration in the chamber based on filter mass of $177 \mu \mathrm{g} \mathrm{m}^{-3}$. A number of particle analyzers were installed in the chamber, including a scanning mobility particle sizer (SMPS) system (TSI 3022A CPC and TSI 3038 DMA) and a Tapered Element Oscillating Microbalance (TEOM) monitor (Rupprecht and Patashnick 1400a series) and typical operating conditions can be found elsewhere (Martin-Reviejo and Wirtz, 2005). The average mass concentrations obtained from the SMPS and the TEOM during the sampling period were 120 and $127 \mu \mathrm{g} \mathrm{m}^{-3}$, respectively. The step-wise addition of cyclohexene may affect the calculation of aerosol yield, but assuming complete consumption of the cyclohexene, the aerosol yield was calculated at $9 \%$, which is in agreement with previous studies (Kalberer et al., 2000).

An area of approximately $3 \mathrm{~mm} \times 9 \mathrm{~mm}$ was removed from the filter and cut into three equal sized pieces for analysis by GCXGC. The small section of filter paper was introduced into a cooled glass $\mathrm{GC}$ injection liner $\left(50^{\circ} \mathrm{C}\right)$, purged with helium and then heated at $20^{\circ} \mathrm{C} \mathrm{min}^{-1}$ in a flow of helium to a maximum of $300^{\circ} \mathrm{C}$, where it was held for $10 \mathrm{~min}$. The organics released in this heating regime were collected in a silica capillary liquid nitrogen cold trap inside the GC oven. Following desorption from the aerosol matrix, the silica capillary trap was removed from the liquid nitrogen and rapidly heated to the oven temperature. Further details can be found elsewhere (Hamilton et al., 2004). GCXGC-TOF/MS was carried out using a cryo-jet Pegasus 4D (Leco, St. Joseph, MI, USA) incorporating an Agilent 6890N Gas Chromatograph and a Pegasus III reflectron time-of-flight mass spectrometer. A liquid nitrogen cooled gas jet midpoint modulator, at approximately $-160^{\circ} \mathrm{C}$, was used to enable comprehensive two-dimensional separations. A secondary oven housed within the GC oven allowed independent column temperature controls. The columns set used in experiments provides a primary volatility based separation followed by a secondary polarity based separation. The first dimension was a 5\% phenyl-95\% methylpolysiloxane $30 \mathrm{~m} \times 320 \mu \mathrm{m} \times 1.0 \mu \mathrm{m}$ HP-5 (J\&W Scientific, Wilmington, DE, USA). The second column was a $50 \%$ phenyl-polysiloxane $2 \mathrm{~m} \times 100 \mu \mathrm{m} \times 0.1 \mu \mathrm{m}$ BP10 
(SGE, Melbourne, Australia). The GC was held at $70^{\circ} \mathrm{C}$ for two minutes and then raised at $2.5^{\circ} \mathrm{C} \mathrm{min}^{-1}$ to $250^{\circ} \mathrm{C}$ and held at this temperature for a further sixteen minutes. The carrier gas was helium $(99.9999 \%$, BOC Gases, Guilford, UK) supplied at $1.5 \mathrm{ml} \mathrm{min}^{-1}$. The modulator and secondary oven were operated at $+30^{\circ} \mathrm{C}$ and $+15^{\circ} \mathrm{C}$ above $\mathrm{GC}$ oven temperature respectively.

The remainder of the filter was placed into $5 \mathrm{ml}$ of HPLC grade methanol (Fisher Scientific, Hampton, NH, USA), the sample vial wrapped in foil to avoid photolysis and left for two hours. This was sonicated for one hour and the methanol extraction filtered using a $0.45 \mathrm{~mm}$ PVDF syringe filter (Whatman). The extract was blown to dryness under a gentle stream of nitrogen and the residue re-dissolved in $1 \mathrm{ml}$ of $0.1 \%$ formic acid in HPLC-MS grade water (Riedel-de Haën, Germany) 50\% methanol solution. Formic acid significantly improved the sensitivity of the analysis, but did not promote any catalytic reactions or artefacts during electrospray ionisation with identical products identified in the absence of the acid. LC-MS/MS analysis was performed using a HCT Plus ion trap mass spectrometer (Bruker Daltonics GmbH, Bremen, Germany) equipped with an Eclipse ODS- $\mathrm{C}_{18}$ column with $5 \mu \mathrm{m}$ particle size (Agilent, $4.6 \mathrm{~mm} \times 150 \mathrm{~mm}$ ). Samples $(40 \mu \mathrm{l})$ were injected via an autosampler (Agilent 1100 series) and a gradient elution was performed using $0.1 \%$ formic acid in HPLC-MS grade water ( $75 \%$ to $40 \%$ over fifteen minutes, hold for ten minutes, return to starting conditions) and pure methanol at $0.6 \mathrm{ml} \mathrm{min}{ }^{-1}$. Electrospray ionisation was carried out at $300^{\circ} \mathrm{C}$, with a nebuliser pressure of $50 \mathrm{psi}$ and nitrogen dry gas flow rate of $12 \mathrm{~L} \mathrm{~min}^{-1}$. The mass spectrometer was used in alternating positive and negative ion mode, scanning from 50 to 1000 Daltons (Da).

High resolution TOF measurements were performed using an electrospray micrOTOF (Bruker Daltonics $\mathrm{GmbH}$, Germany). Chromatographic conditions were identical to those used previously. $10 \mu \mathrm{l}$ aliquots of the samples were injected via an autosampler (Agilent 1100 series). Negative ion electrospray ionisation was carried out at a source temperature of $200^{\circ} \mathrm{C}$, nebuliser pressure of $1.0 \mathrm{Bar}$ and a nitrogen dry gas flow rate of $71 \mathrm{~min}^{-1}$. The scan range used was 50 to $800 \mathrm{Da}$. The data was externally calibrated using an average spectrum of sodium formate clusters automatically injected at the start of the chromatographic run.

\section{Results}

\subsection{GCXGC analysis}

Initial analysis of the cyclohexene SOA was carried out using thermal desorption coupled to GCXGC-TOF/MS and an example chromatogram is shown in Fig. 1. The chromatogram is presented as a contour plot with the retention times on columns 1 and 2 on the $\mathrm{X}$ - and $\mathrm{Y}$-axis and the response as a coloured contour. Each spot on the chromatograms rep-

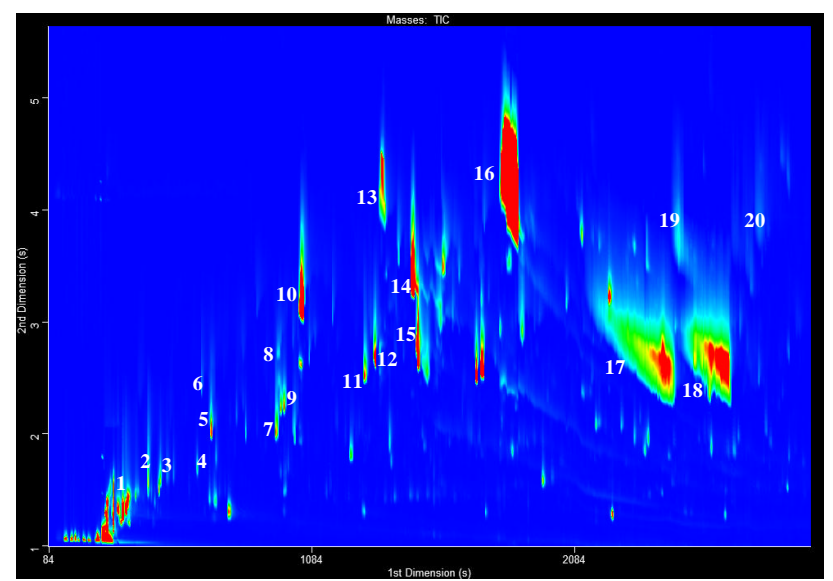

Fig. 1. Total ion chromatogram obtained by thermal desorptionGCXGC-TOF/MS of a cyclohexene ozonolysis aerosol sample. Peak identifications are given in Table 1.

resents an individual compound with a full mass spectrum. Increasing retention times on columns one and two indicate decreasing volatility and increasing polarity respectively. A total of 45 analytes were identified and structures are given in Table 1.

The chromatogram is dominated by di-carboxylic acids (glutaric $\mathrm{C}_{5}$ and adipic $\mathrm{C}_{6}$ ) and their corresponding cyclic anhydrides. The majority of the identified mass is accounted for by a small number of compounds, unlike previous studies of toluene SOA where no one compound or functionality dominated (Hamilton et al., 2005). In addition, a number of ring-retained compounds were identified, including cyclohexanone, cyclohexanol, 1,2-cyclohexandiol, 1,2-cyclohexandione and 2-hydroxy-cyclohexanone. Large numbers of cyclic products, formed via a ring cleavage process, were also found including both 5 and 6 membered rings such as cyclopentanones, cyclopentenones, lactones, pyranones and bicyclic species. Dihydro-2(3H)-furanone and tetrahydro-2H-pyran-2-one are most likely the result of dehydration and internal cyclisation of the corresponding terminal hydroxy-acid (4-hydroxy-butanoic acid and 5-hydroxypentanoic acid) which is known to occur rapidly on formation (Kimura et al., 2003). The hydroxyl-acids are extremely difficult to make, preferring the lactone configuration.

Many previous studies of SOA composition use derivatization to convert polar groups to less polar functionalities to make them more suitable for GC analysis. Popular derivatization agents used include PFBHA (O-(2,3,4,5,6-pentafluorobenzyl)-hydroxamine) and BSTFA (N,O-bis(trimethylsilyl)-trifluoroacetamide), which convert carbonyl groups and carboxyl/hydroxyl groups respectively. The derivatized analytes are well suited to GC and produce good peak characteristics although cyclic compounds, such as those identified in this study, do not react with these derivatization compounds and would potentially not be re- 
solved. In this work the use of thermal desorption to release semi-polar compounds from the aerosol removes the use of polar solvents which can cause solvent effects (such as peak tailing, broadening or splitting) and hence the loss or reaction of compounds during GC analysis (Fowlis, 1995). Thermal desorption and GC in general has a limited polarity range, obvious in the tailing, peak shape of glutaric and adipic acid in Fig. 1. More volatile di-acids, such as oxalic and malonic acid cannot be identified using this technique as they are lost to surfaces within the liner and degrade on column.

Some previous studies have shown that acyclic species can undergo dehydration and cyclisation during GC injection at high temperatures. The thermal desorption method only exposes compounds to temperatures sufficient to volatise them from the filter, but there is the possibility of artefacts. In order to test that the remaining cyclic compounds identified in this study are actually in the filter particles and are not products of cyclisation-dehydration reactions, a series of standard mixtures were spiked onto the filter paper. These were then subjected to the same thermal desorption process as the samples. None of the standard solutions (succinic acid, glutaric acid, adipic acid, 4-oxo-2-pentenal, levulinic acid, maleic acid, 4acetyl butyric acid and DL-Hydroxy-capric acid) showed any indication of in-inlet cyclisation and although this list does not cover all the possible compounds which would form the species identified by GCXGC, the filter desorption method does not seem to cause artefacts through cyclisation reactions of stable individual acyclic compounds.

The formation of the cyclic compounds is difficult to rationalise from known reaction mechanisms. Although, they are not formed through in-inlet cyclisation of individual acylic compounds, there is the possibility that any oligomer compounds which break down during analysis could also undergo this type of reaction. Many of the species identified by GCXGC are difficult to mechanistically link to known cyclohexene ozonolysis pathways. They may be formed via an interaction of the cyclohexene or one of its ozonolysis products with the aerosol phase itself. In-aerosol chemistry is currently very poorly understood.

A number of unidentified peaks were found with this technique and interpretation of their mass spectra proved inconclusive. However, fragmentation patterns with losses of 14 $\left(\mathrm{CH}_{2}\right), 16(\mathrm{O})$ and $28(\mathrm{CO})$ mass units suggest an oxidised hydrocarbon backbone. Compounds with fragments as large as $166 \mathrm{Da}$ were seen, and cannot be accounted for without "mass adding" heterogeneous reactions. It was not possible to identify any large molecules using the GCXGC analysis. Oligomers may fragment during the thermal desorption or during ionisation. They may also be involatile at the thermal desorption temperatures used here and remain within the inlet as a residue.
Table 1. Low molecular weight reaction products identified in cyclohexene ozonolysis SOA using GCXGC-TOF/MS.

\begin{tabular}{|c|c|c|c|}
\hline Identified analyte & Mass & Peak on GCXGC & Structure \\
\hline \multicolumn{4}{|l|}{ LINEAR } \\
\hline \multicolumn{4}{|l|}{ ALDEHYDES and KETONES } \\
\hline butanal & 72 & 1 & o \\
\hline pentanal & 86 & 3 & \\
\hline hexanal & 100 & 4 & \\
\hline 2-propenal & 56 & & \\
\hline 2-butenal & 70 & & \\
\hline 2-hexenal & 98 & & \\
\hline 3-hydroxy-butenal & 86 & & \\
\hline butanedial & 86 & & \\
\hline hexanedial & 114 & 12 & \\
\hline 2-hexanone & 100 & & \\
\hline \multicolumn{4}{|l|}{ ACIDS } \\
\hline propanoic acid & 74 & & \\
\hline butanoic acid & 88 & 6 & \\
\hline pentanoic acid & 102 & 8 & \\
\hline hexanoic acid & 116 & & \\
\hline butandioc acid (succinic acid) & 118 & & \\
\hline pentandioc acid (glutaric acid) & 132 & 17 & \\
\hline hexandioc acid (adipic acid) & 146 & 18 & \\
\hline \multicolumn{4}{|l|}{ OTHERS } \\
\hline butanol & 74 & 2 & \\
\hline 2-butene-1,4-diol & 88 & & $\mathrm{HO}^{-1}$ \\
\hline 2-butoxyethanol & 118 & & $\widehat{\mathrm{OH}}$ \\
\hline hexanoic acid anhydride & 214 & 20 & \\
\hline
\end{tabular}

\subsection{LC-ESI MS/MS analysis}

The methanol extracts of cyclohexene SOA were analysed using LC-MS/MS in both the negative and positive ionisation modes and the base peak chromatograms are shown in Fig. 2. The base peak chromatogram is a representation of the most intense single ion at each scan point and this ion mass is shown for each peak. A blank filter was also extracted but the chromatogram showed no significant peaks above the noise. Positive ionisation mode had the highest sensitivity but the majority of ions had formed adducts with $\mathrm{Na}^{+}$and $\mathrm{K}^{+}$, which provided poor fragmentation patterns and was not used further in this study. The difference of $24 \mathrm{Da}$ between the peaks labelled on the positive and negative chromatograms is due to the $\mathrm{Na}^{+}$adduct in the positive ionisation mode.

Analytes with molecular masses below $200 \mathrm{Da}$ dominate the early part of the chromatogram. Structural analysis of fragmentation patterns and comparison with standard solutions resulted in the detection of 7 low molecular weight 
Table 1. Continued.

\begin{tabular}{|c|c|c|c|}
\hline Identified analyte & Mass & Peak on GCXGC & Structure \\
\hline CYCLICS & & & \\
\hline Cyclohexanone & 98 & 9 & \\
\hline 1,2-cyclohexandione & 112 & & \\
\hline 2-hydroxy-cyclohexanone & 114 & 11 & \\
\hline cyclohexanol & 100 & 7 & \\
\hline 1,2-cyclohexandiol & 116 & 15 & \\
\hline formic acid cyclohexyl ester & 128 & & \\
\hline cyclohexen-2-one & 96 & & \\
\hline 1-4-cyclohexen-2-dione & 110 & & \\
\hline cyclopentanone & 84 & 5 & \\
\hline cyclopentane carboxaldehyde & 98 & & \\
\hline 2-methyl-cyclopentanone & 98 & & \\
\hline cyclopentenone & 82 & & \\
\hline cyclopentendione & 96 & & \\
\hline dihydro-2(3H)-furanone & 86 & 10 & \\
\hline $2(5 \mathrm{H})$-furanone & 84 & & \\
\hline $\begin{array}{l}\text { dihydro-5-methyl-2(3H)- } \\
\text { furanone }\end{array}$ & 100 & & \\
\hline 2,5-furandione & 98 & & \\
\hline $\begin{array}{c}\text { 2,5-dihydro-furandione (succinic } \\
\text { anhydride) }\end{array}$ & 100 & 13 & \\
\hline
\end{tabular}

\begin{tabular}{|c|c|c|c|}
\hline Identified analyte & Mass & Peak on GCXGC & Structure \\
\hline $\begin{array}{c}\text { CYCLICS cont. } \\
\text { 5-oxotetrahydro-furan-2- } \\
\text { carboxylic acid }\end{array}$ & 128 & 19 & 14 \\
\hline $\begin{array}{c}\text { tetrahydro-2H-pyran-2-one } \\
\text { dihydro-2H-pyran-2,6-(3H)- } \\
\text { dione }\end{array}$ & 100 & 16 & \\
\hline $\begin{array}{c}\text { 2-oxepanone } \\
\text { 6-oxo-bicyclo[3.1.0]hexan-3-one }\end{array}$ & 98 & 114 & \\
\hline 7-oxobicyclo[4.1.0]heptane & 98 & \\
\hline 6,8-dioxabicyclo[3.2.1] octane & 114 & \\
\hline
\end{tabular}

acids. Peak identifications are shown in Table 2 and correspond to the following products: glutaric acid, adipic acid, 6-oxohexanoic acid, 3,6-dihydroxy-5-oxohexanoic acid, dioxohexanoic acid, hydroxy-glutaric acid and hydroxy-adipic acid. The position of the hydroxyl or carbonyl group on the final three analytes cannot be determined using this technique. The most abundant molecules found during the GCXGC analysis, i.e. the di-acids and their derivatives, also account for the majority of small molecules identified in the LC analysis, highlighting the complimentary nature of the two techniques. The aldehyde and cyclic compounds identified in GCXGC were not found in the LC analysis. This is due to a combination of poor ionisation of these species during electrospray and individual concentrations below the detection limit of the LC system.

These acids have previously been identified as some of the major components of SOA formed during cyclohexene ozonolysis and can be mechanistically linked to the par-

ent hydrocarbon, via a number of reaction pathways. A total of 16 di-carboxylic acids, hydroxy-acids, oxo-acids, di-aldehydes and pentanal were quantified in Kalberer et al. (2000) and were found to account for almost all of the aerosol volume, based on an aerosol density of $1.4 \mathrm{~g} \mathrm{~cm}^{-3}$. Gao et al. (2004a) identified a total of 20 low molecular weight species in cyclohexene- $\mathrm{O}_{3} \mathrm{SOA}$, which were calculated to account for $42 \%$ of the total SOA mass. A further $3 \%$ was attributed to oligomeric structures. This discrepancy was attributed partly to the use of different $\mathrm{OH}$ scavengers (CO versus cyclohexane) producing different $\mathrm{HO}_{2}$ to $\mathrm{RO}_{2}$ ratios in the reaction system. This study uses $i$-propanol as the $\mathrm{OH}$ scavenger, so is different from either study. Other factors that may produce artefacts include the use of denuders, different filters and sampling preparation techniques.

Although no direct quantification was carried out in this study (since for many species no standard or authentic compound exists), it is clear from Fig. 2 that these early gen- 
Table 2. Low molecular weight reaction products in cyclohexene ozonolysis SOA extract identified using LC-MS/MS.

\begin{tabular}{|c|c|c|c|c|}
\hline Identified analyte & $\begin{array}{c}{[\mathrm{M}-\mathrm{H}]} \\
\mathrm{m} / \mathrm{z} \text { ratio }\end{array}$ & Mass & 129 & 130 \\
\hline 6-Oxo-hexanoic acid & 143 & 144 & 132 & 146
\end{tabular}

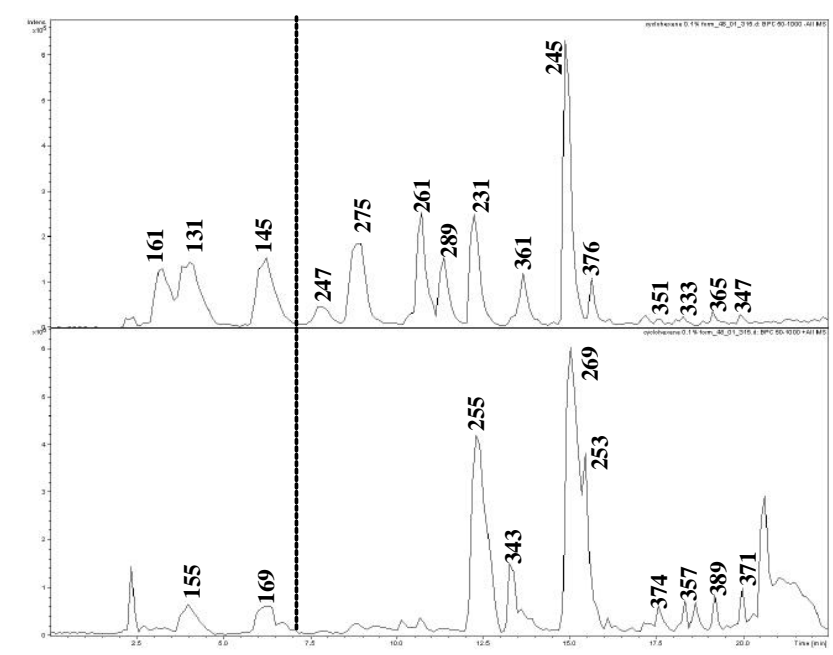

Fig. 2. Electrospray LC-ion-trap MS chromatograms of the cyclohexene SOA methanol extract. Upper: Negative ionisation mode. Lower: Positive ionisation mode. Labels correspond to the most abundant ion for each peak.

eration ozonolysis products account for perhaps less than half of the overall aerosol composition. The intensity of the base peak chromatograms suggests that the majority of compounds identified have a molecular mass greater than $200 \mathrm{Da}$ and are likely the result of combination reactions either heterogeneously with the aerosol or in the gas phase. The dotted line on the chromatograms indicates the shift from small monomer type compounds to dimers, formed using the monomer building blocks. Standard mixtures of di-acids, oxo-acids and hydroxyl-acids show no degradation or reaction during electrospray ionisation indicating that the high operating temperatures are not a source of oligomers. Using a tandem MS approach with an ion-trap, the two most abundant ions at each survey scan at any point on the chromatogram are isolated and undergo one stage of collision induced fragmentation $\left(\mathrm{MS}^{2}\right)$. Using the product ion mass spectra (i.e. $\mathrm{MS}^{2}$ ), a detailed structural analysis of each peak was carried out and confirmed the most abundant peaks as dimers.

The four most abundant dimers found correspond to precursor ion masses of 231,245, 261 and $275 \mathrm{~m} / z$ and the MS and product ion mass spectra are shown in the top half of Figs. 3-6. Due to the limited number of fragment ions produced for these species an exact structural identification could not be obtained, only a reduction in possible chemical structure possibilities. Sufficient data was available to determine the possible molecular formulas for each peak, shown in Table 3. Each molecular formula is accompanied by one of the most likely dimer structures, assuming they are composed of the most abundant low molecular weight compounds identified in the SOA using GCXGC and LCMS. The monomer pair that would form the example structures is also shown in Table 3. In some cases, such as the $\mathrm{C}_{7} \mathrm{H}_{2} \mathrm{O}_{10}$ molecular formula for $\mathrm{M}=246 \mathrm{Da}$, the chemical structure given is the only possible isomer.

The largest peak in the chromatogram corresponds to a $[\mathrm{M}-\mathrm{H}]^{-}$of $245 \mathrm{Da}$ and the mass spectrum and product ion mass spectrum are shown are Fig. 3a. The 245 ion dissoci- 
Table 3. Proposed dimer structures of peaks identified in LC-MS/MS chromatogram. Possible molecular formulas and corresponding dimer-monomer pairs are shown for each mass.

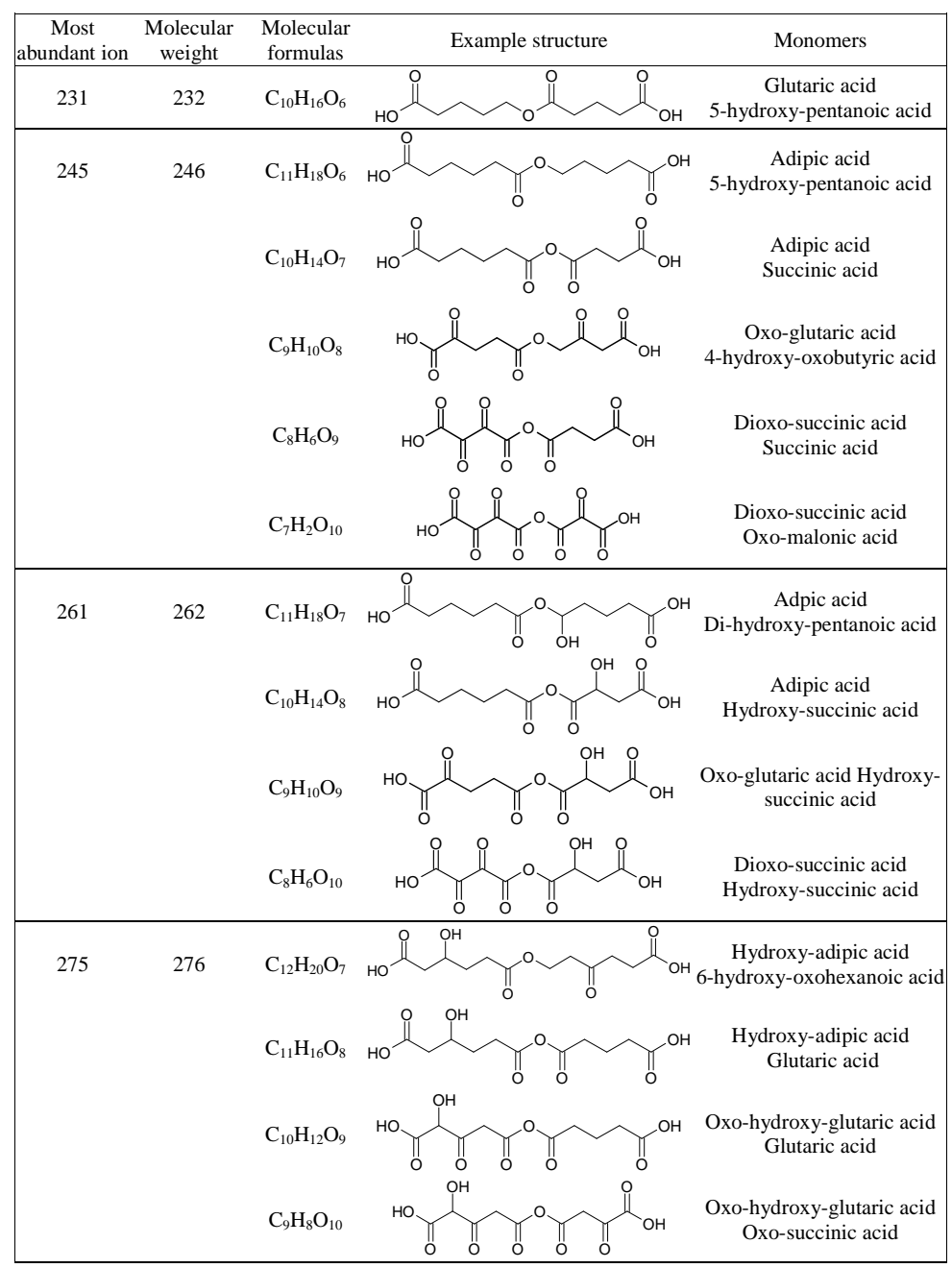

ates to the fragment ions of $145,127,117,101,83 \mathrm{Da}$ and two structures, with different molecular formulae, that fit the required fragments are shown in the lower half of Fig. 3. In the case of all the possible molecular formulae, the linkage between the monomer units is either ester or anhydride functionality. Although the end groups may have differing combinations of $\mathrm{C}, \mathrm{H}$ and $\mathrm{O}$, to match the mass spectrum, the linkage can only be via one of these two functional groups. In practice the spectra could well be composed of both functional types as a mixture.

The mass resolution of the ion-trap mass spectrometer is insufficient to differentiate between the five proposed molecular formulae for $[\mathrm{M}-\mathrm{H}]^{-}=245 \mathrm{Da}$. However, due to the different atomic combinations, they have slightly different accurate mass values e.g. $\mathrm{C}_{11} \mathrm{H}_{18} \mathrm{O}_{6}=246.261726$ and $\mathrm{C}_{7} \mathrm{H}_{2} \mathrm{O}_{10}=246.087894 \mathrm{Da}$. The cyclohexene extract was analysed on a micrOTOF, a time-of-flight mass spectrome- ter with a resolution of 10000 . This allows the measurement of accurate mass to $1 \mathrm{mDa}$, and to differentiate between two ions of similar nominal mass. As the isobaric compounds were separated in time by chromatography, the resolution aspect was less important than the accurate mass. The spectra contained information not only on the accurate mass, but also isotope ratios. The combinations of these two pieces of information were used to narrow down a theoretical list of potential formula to give a confident compound identification.

Using accurate mass measurements, the molecular formula of the most abundant compound with $\mathrm{M}=246 \mathrm{Da}$ was confirmed as $\mathrm{C}_{11} \mathrm{H}_{18} \mathrm{O}_{6}$. With this information and the $\mathrm{MS}^{2}$ fragmentation data in both the negative and positive ionisation modes, the only possible linkage of the two reactants is an ester, with the most likely structure being a dimer of adipic acid and 5-hydroxy-pentanoic acid. The extracted ion chromatogram obtained on the micrOTOF for $[\mathrm{M}-\mathrm{H}]^{-}=245 \mathrm{Da}$ 

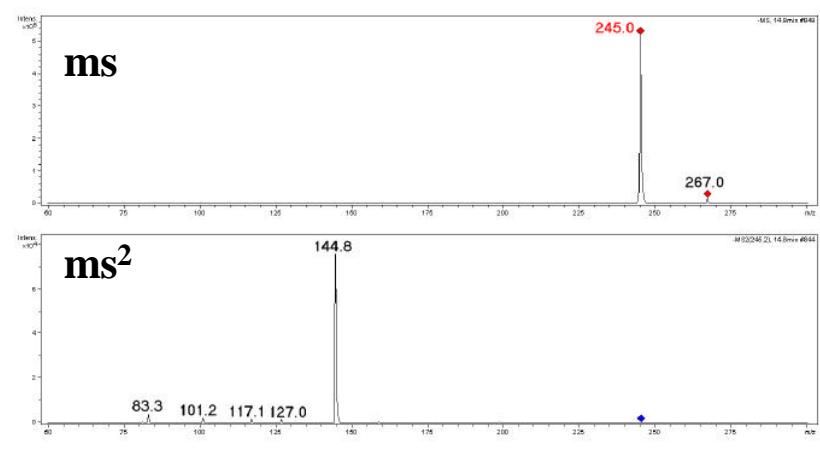

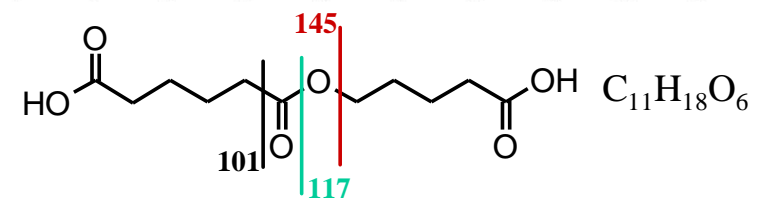<smiles>O=C(O)CCC(=O)OC(=O)C(=O)C(=O)C(=O)O</smiles>

Fig. 3. Mass spectral data and structural analysis of peak with [M$\mathrm{H}]^{-}$of $245 \mathrm{Da}$. Top: MS spectrum at peak apex. Middle: Collision induced dissociation product ion spectrum. Bottom: Two possible structures that explain the $\mathrm{MS}^{2}$ fragmentation. High mass resolution spectrometry indicates that the upper structure has the correct molecular formula and is most likely.
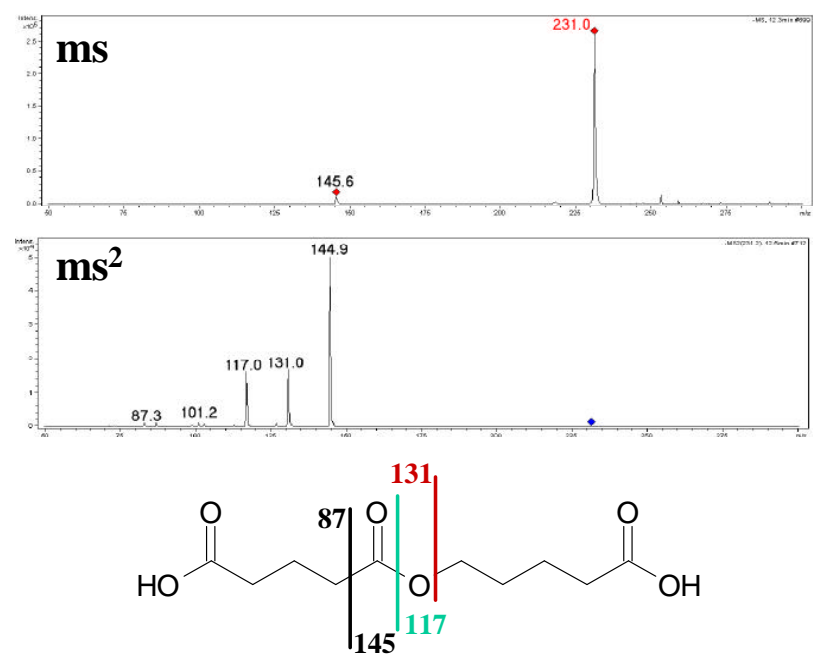

Fig. 4. Mass spectral data and structural analysis of peak with [M$\mathrm{H}^{-}$of $231 \mathrm{Da}$. Top: MS spectrum at chromatographic peak apex. Middle: Collision induced dissociation product ion spectrum. Bottom: Proposed structure, fragments that explain $\mathrm{MS}^{2}$ spectrum are shown.

is shown in Fig. 7. Although the $\mathrm{C}_{11} \mathrm{H}_{18} \mathrm{O}_{6}$ peak is the largest in the chromatogram, more oxidised compounds are also present, and their possible structures are given in Ta-
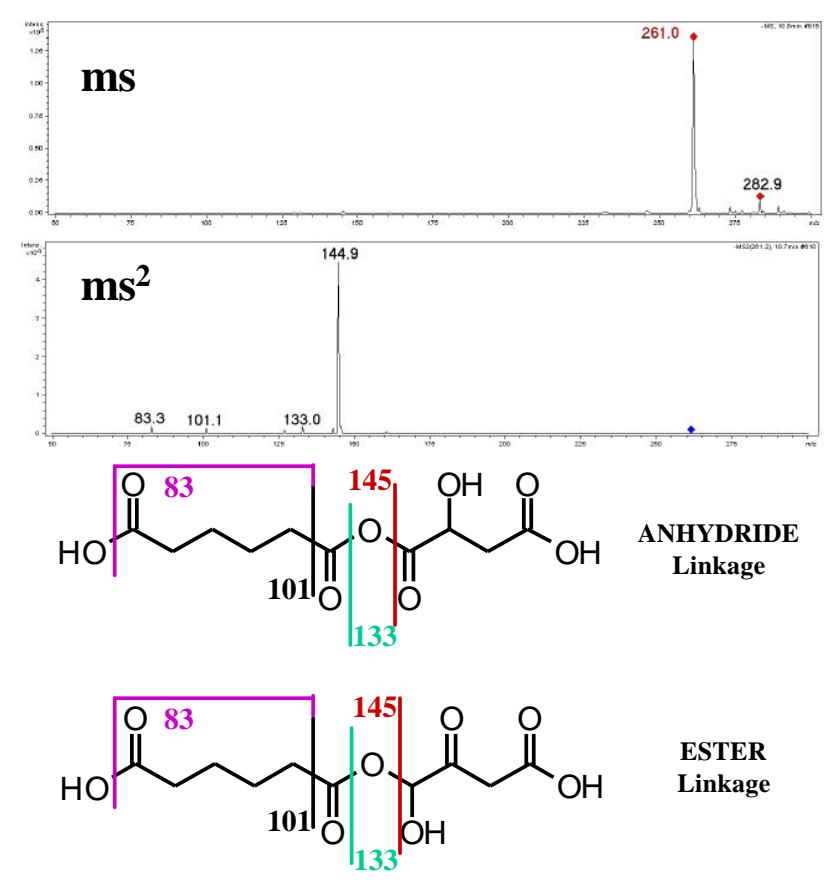

Fig. 5. Mass spectral data and structural analysis of peak with [M$\mathrm{H}]^{-}$of $261 \mathrm{Da}$. Top: MS spectrum at peak apex. Middle: Collision induced dissociation product ion spectrum. Bottom: Proposed structures with ester (upper) and acid anhydride (lower) linkages. Both structures can explain $\mathrm{MS}^{2}$ spectrum and have correct molecular formula.

ble 3. $\mathrm{MS}^{2}$ spectra are not available for these compounds due co-elution with more abundant ions.

Accurate mass measurement and the product ion mass spectrum for $[\mathrm{M}-\mathrm{H}]^{-}=231 \mathrm{Da}$, indicate that this compound is an analogue of the previous dimer, with one less $\mathrm{CH}_{2}$ group i.e. $\mathrm{C}_{10} \mathrm{H}_{16} \mathrm{O}_{6}$. Combining accurate mass and tandem MS data again gives the most likely structure as the ester of glutaric acid and 5-hydroxy-pentanoic acid, shown in Fig. 4.

The next most abundant peaks correspond to 261 and 275 Daions. Accurate mass measurements indicate these compounds are more oxidised both containing 8 oxygen atoms $\left(\mathrm{C}_{10} \mathrm{H}_{14} \mathrm{O}_{8}\right.$ and $\mathrm{C}_{11} \mathrm{H}_{16} \mathrm{O}_{8}$ respectively). The linkage between monomer units can be either an ester or an acid anhydride depending on the position of the carbonyl groups and example structures are shown in Figs. 5 and 6. The combination of MS techniques in this case is unable to determine exactly the linkage, but can reduce the number of possibilities to either the ester or acid anhydride or a mixture of both types may be present. It is clear that the composition of heterogeneous reaction products is reasonably complex, with single ion masses being most likely made up of a mixture of different molecular formulae. The power of LC is certainly required to isolate individual compounds with the same nominal mass but varying degrees of oxidation, which are not possible using techniques based on ionisation alone. 

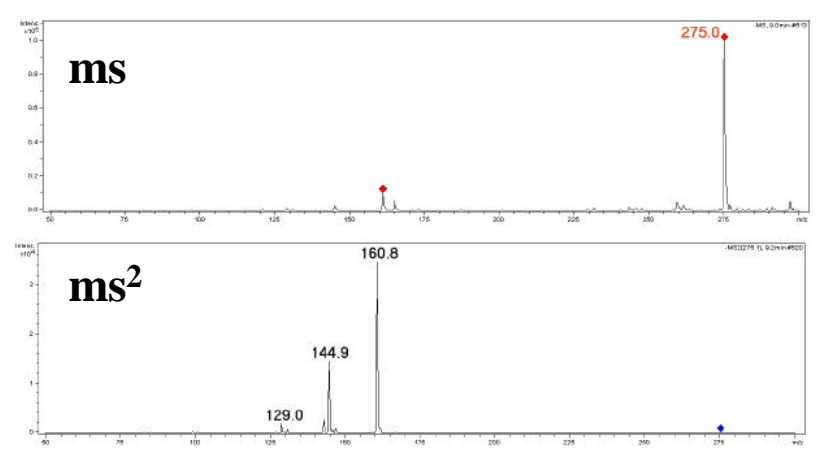<smiles>CCCCCC(=O)OC(=O)CCCC(=O)O</smiles><smiles>CC(CC(=O)CC(=O)O)OC(=O)CCC(O)CC(=O)O</smiles>

Fig. 6. Mass spectral data and structural analysis of peak with [M$\mathrm{H}]^{-}$of 275 Da. Top: MS spectrum at peak apex. Middle: Collision induced dissociation product ion. Bottom: Proposed structures with ester (upper) and acid anhydride (lower) linkages. Both structures can explain $\mathrm{MS}^{2}$ spectrum and have correct molecular formula.

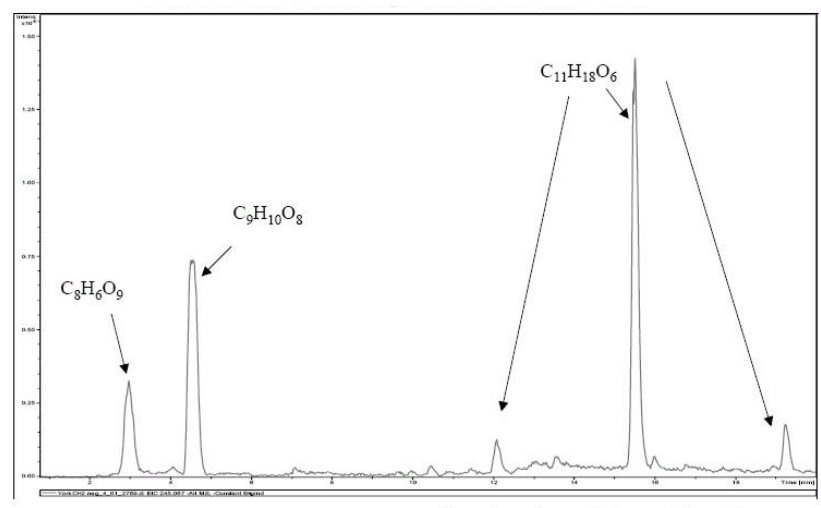

Formulae given refer to neutral species

Fig. 7. Extracted ion chromatogram for $m / z$ 245, obtained using high resolution micrOTOF detector. Peaks are labelled with the associated molecular formulae.

Although the main peaks identified from tandem MS correspond generally to the least oxidised structures in Table 3, high resolution mass spectrometry indicates that the majority of molecular formulae proposed in Table 3 are present in this SOA. Only the 4 most abundant dimers have been discussed and they all represent di-acid oligomers. A total of 18 dimers were identified and the mass spectra indicate that end groups can be either acid or aldehyde and all combina-
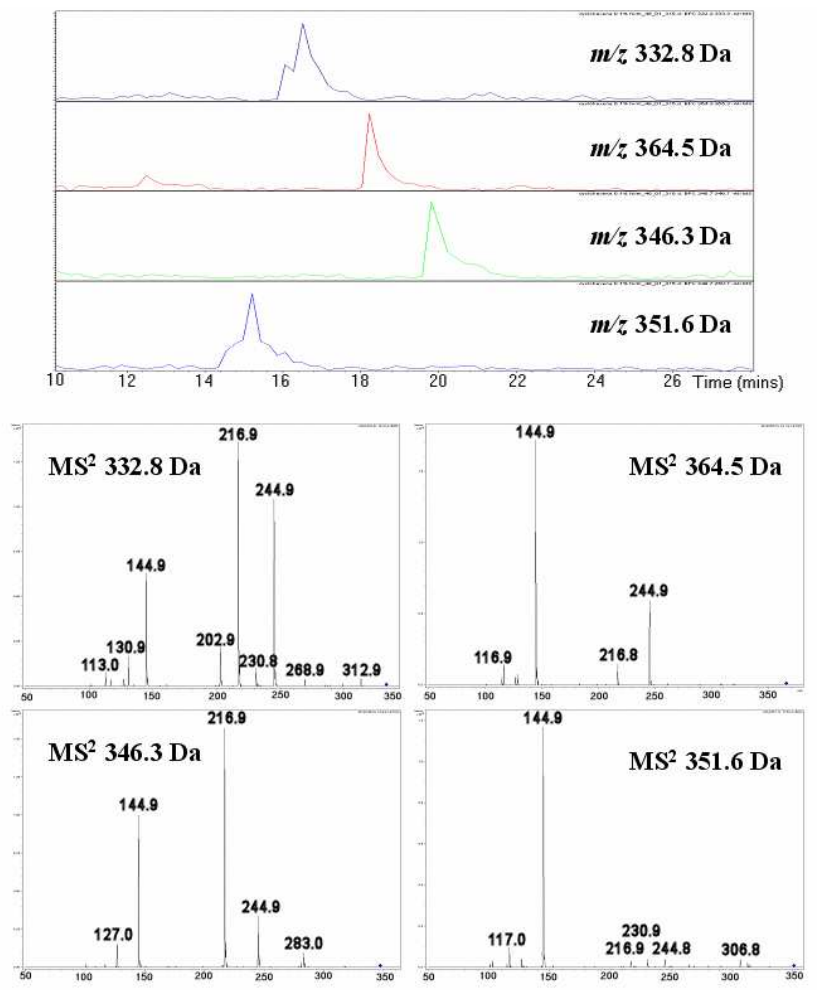

Fig. 8. Upper: Extracted ion chromatograms for $m / z 332.8$ (black), 264.5 (red), 346.3 (green), and 351.6 Da (blue). Lower: Product ion mass spectrum for each peak.

tions were found (i.e. acid-acid, acid-aldehyde and aldehydealdehyde).

The smaller peaks at the end of the separation are difficult to see above the noise, with many low concentration species eluting together to give an elevated baseline. Plotting single ion chromatograms allows individual peaks to be extracted from this baseline. The region of the chromatogram between 15 and $24 \mathrm{~min}$ has been expanded and individual ion chromatograms for 4 masses are shown in Fig. 8. These later peaks correspond to molecules with a molecular mass greater than $300 \mathrm{Da}$. The product ion mass spectra for the four peaks are shown in the lower region of Fig. 8. The product ion mass spectra have a common set of product ions 145,217 and $245 \mathrm{Da}$ - indicating that they have related structures. Indeed the 145 fragment corresponds to an ionised [M$\mathrm{H}]$ adipic acid group and is seen in many of the dimers also. Structural analysis of the product ion mass spectra is inconclusive but suggests that these peaks are mixtures of trimers and tetramers, which cannot be individually separated by the LC system used here.

Gao et al. (2004) proposed three possible mechanisms for the formation of oligomers in the ozonolysis of cycloalkanes: aldol reaction, gem-diol reaction and acid dehydration. The last would form acid anhydrides similar to those identified above. A very recent study of isoprene oxidation (Surratt et al., 2006) identified polyesters, formed via an esterfi- 

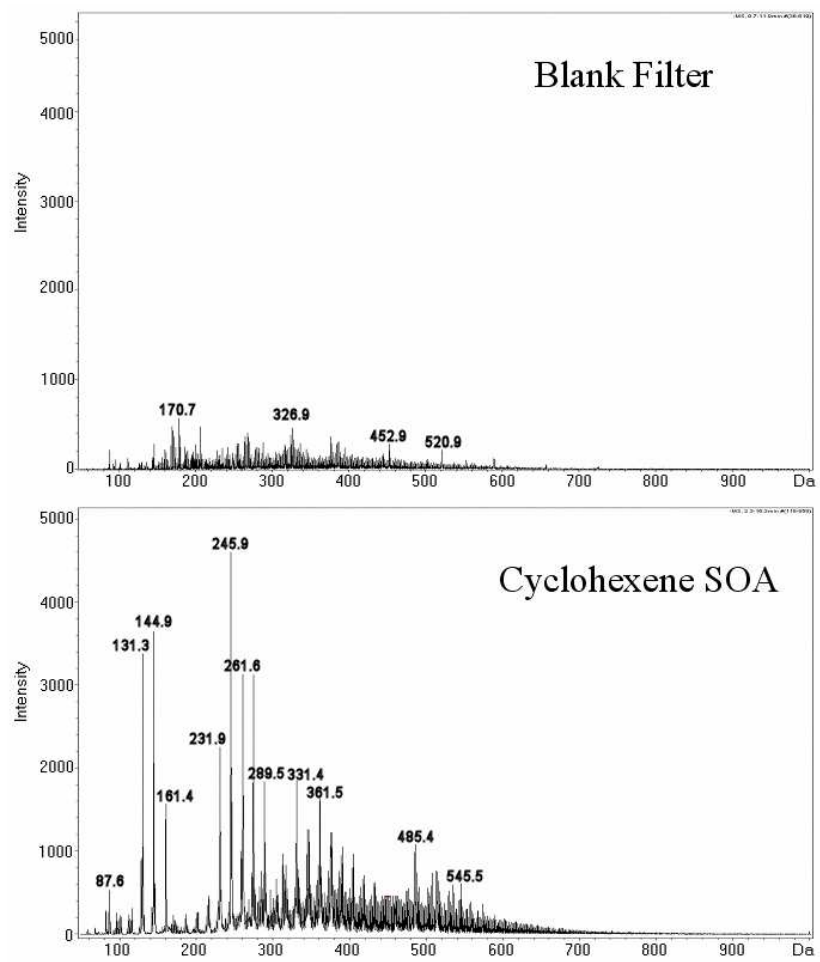

Fig. 9. Averaged mass spectrum across the entire LC chromatogram. Upper: Blank filter. Lower: Cyclohexene ozonolysis aerosol.

cation reaction of the oxidation product methacrolein with hydroxyl groups, with 2-methylglyceric acid being a key monomeric species. Barsanti and Pankow (2006) have developed a general theoretical approach to evaluate the thermodynamic favourabilities of accretion reactions. It was concluded that for the acids studied (acetic, malic, maleic, pinic) and likely for similar mono-and di-carboxylic acids, significant SOA formation could occur via ester formation in the atmosphere, when kinetically favourable. The formation of oligomers with esters and acid anhydride functionalities can significantly increase partitioning to the aerosol phase.

A number of formation mechanisms for oligomers in SOA have been proposed in addition to esterfication and acid dehydration. These are based on the identification of oligomers, such as di-acylperoxides, peroxyhemiacetals, $\alpha$-acyloxyalkyl hydroperoxides and di-peroxides, during the ozonolysis of alkenes (Docherty et al., 2005; Zahardis et al., 2006; Ziemann 2002; Ziemann 2003; Ziemann 2005). These species are formed via the reaction of the stabilised Criegee intermediate, or its degradation products, with carbonyls, alcohols or acids. No evidence of these compounds was found in the cyclohexene ozonolysis SOA in this study. The mass spectra and molecular formulae together indicate that these species are not present. As an example, for $\mathrm{M}=246$ and $\mathrm{C}_{11} \mathrm{H}_{18} \mathrm{O}_{6}$, the di-acylperoxide would have either $\mathrm{A}$ ) aldehyde at one end and a hydroxyl at the other end, or B) acid at one end and
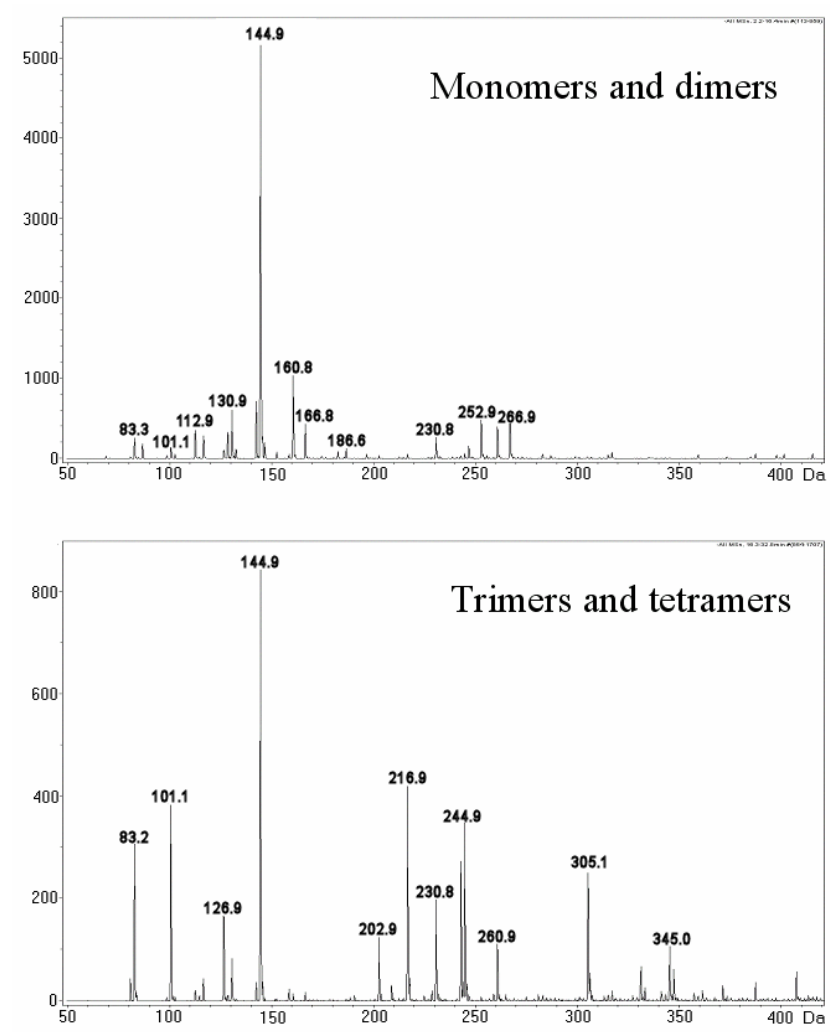

Fig. 10. Average product ion mass spectrum across the entire LC chromatogram. Upper: Monomer and dimer region. Lower: Trimer and tetramers region.

methyl at the other end. Neither of these can easily be rationalised from the reaction mechanism. In addition, the most likely site for cleavage during fragmentation would be at the peroxide bond. This would not match the mass spectrum obtained. For analytes with unknown molecular formulae, the mass spectra also do not indicate the occurrence of any of these classes of compounds. The lower precursor concentrations used in this study may also reduce the amount of oligomers formed through reactions of the stabilised Criegee intermediate.

In order to obtain a profile of the total molecular mass distribution of SOA components, the average mass spectra across the entire chromatogram can be combined. This approach provides a "view" of chemical composition similar to that obtained using techniques such as MALDI. A comparison of the mass distribution profiles (negative ion mode) from the extracted blank filter and the cyclohexene SOA are shown in Fig. 9. This average mass spectra is very similar to that obtained by directly infusing the sample into the ESI-ion trap without any LC separation. The blank filter provides a background mass spectrum, where there is no obvious structure, the maximum intensity is 600 counts and most masses are below 400 counts. The cyclohexene SOA mass spectrum shows the expected major larger ion peaks $14\left(\mathrm{CH}_{2}\right)$ and $16(\mathrm{O}) \mathrm{Da}$ 
apart. The high intensity 131,145 and 161 Da ions correspond to glutaric acid, adipic acid and hydroxy-adipic acid identified earlier. The monomer and dimers dominate the mass spectrum (in the same way they dominate when viewed as individual chromatographic peaks) but it is clear that a significant amount of aerosol mass resides in an oligomeric form, with ion fragments above the background up to at least $600 \mathrm{Da}$. These oligomeric compounds are found in low concentrations and do not undergo $\mathrm{MS}^{2}$ fragmentation, due to overlapping with more abundant analytes during the LC separation and insufficient sensitivity of the ion-trap during syringe infusion. The SOA resolved in this paper was produced during the first hour after initial aerosol was detected and indicates that heterogeneous reactions do begin to occur early in the formation and ageing process. Although the monomer and dimers dominate the SOA composition, within an hour molecules up to $600 \mathrm{Da}$ have already formed.

The total chromatogram mass spectra shown in Fig. 9 can also be plotted for the product ion mass spectra to give an indication of the most common fragments / monomers. The $\sum \mathrm{MS}^{2}$ was plotted for the monomer-dimer (Rt 2.0-Rt 16.0) and trimer-tetramer (Rt 16-Rt 32.8) regions of the chromatogram and are shown in Fig. 10. The monomer-dimer product ion mass spectrum is dominated by fragment $145 \mathrm{Da}$ (adipic acid) and other low molecular weight species. The trimers-tetramers spectrum shows both monomer and dimer groups, and is again dominated by $145 \mathrm{Da}$ (and its fragmentation products - loss of $-\mathrm{OH}_{2}=127 \mathrm{Da}$, loss of $-\mathrm{CO}_{2}=101 \mathrm{Da}$ and loss $\left.-\mathrm{OH}_{2}+\mathrm{CO}_{2}=83 \mathrm{Da}\right)$. It is clear that although the SOA composition formed from this precursor ion is time consuming to resolve, only a limited number of key chemical fragments are needed to describe much of the composition. This demonstrates that only a small subset of possible early stage small molecule SOA products found in the GCXGC and LC analysis take part in the heterogeneous reactions in the early stages of aerosol processing - in this case of cyclohexene it is adipic acid that is commonly incorporated to larger molecules. This would suggest that in the future it may prove feasible to construct a detailed precursor specific chemical SOA formation scheme in the manner used in master chemical mechanisms for the gas phase.

\section{Conclusions}

The composition of the secondary organic aerosol formed during the ozonolysis of cyclohexene has been investigated and it was determined that the majority of the organic mass was composed of di-carboxylic acids, cyclic anhydrides and dimer molecules, formed through reactions of the most abundant small acids. Tandem mass spectrometry indicated the predominate linkage between monomer units as either esters or acid anhydrides. Trimers and tetramers were identified but could not be structurally assigned. High resolution mass spectrometry allowed the exact molecular formulae of the most abundant dimers to be determined, structures which can only be accounted for by mass adding heterogeneous reactions. Although the aerosol analysed was collected relatively early in the ageing process, molecules up to $600 \mathrm{Da}$ were found. Fragmentation of larger molecules produced a limited number of product ions, indicating that only a subset of gas phase reaction products undergo heterogeneous reactions.

Acknowledgements. Thanks go to K. Wirtz and the team at the Fundación Centro de Estudios Ambientales del Mediterráneo (CEAM) in Valencia, Spain. Thanks go to $\mathrm{M}$. Vazquez an E. Borras Garcia for providing the SMPS data and protocols for the experiment. Thanks to Bruker Daltonics for high-resolution mass spectrometric analysis. This research was funded by the NERC grant (NE/B50582X/1).

Edited by: M. Ammann

\section{References}

Andreae, M. O. and Crutzen, P. J.: Atmospheric aerosols: Biogeochemical sources and role in atmospheric chemistry, Science, 276, 1052-1058, 1997.

Artaxo, P., Storms, H., Bruynseels, F., Vangrieken, R., and Maenhaut, W.: Composition and Sources of Aerosols from the Amazon Basin, J. Geophys. Res., 93, 1605-1615, 1988.

Bahreini, R., Keywood, M. D., Ng, N. L., Varutbangkul, V., Gao, S., Flagan, R. C., Seinfeld, J. H., Worsnop, D. R., and Jimenez, J. L.: Measurements of secondary organic aerosol from oxidation of cycloalkenes, terpenes, and m-xylene using an Aerodyne aerosol mass spectrometer, Environ. Sci. Technol., 39, 5674-5688, 2005.

Barsanti, K. C. and Pankow, J. F.: Thermodynamics of the formation of atmsopheric organic particulate matter by accretion reactions - Part 3: Carboxylic and dicarboxylic acids, Atmos. Environ., 40, 6676-6686, 2006.

Docherty, K. S., Wu, W., Lim, Y. B., and Ziemann, P. J.: Contributions of organic peroxides to secondary aerosol formed from reactions of monoterpenes with O-3, Environ. Sci. Technol., 39, 4049-4059, 2005.

Forstner, H. J. L., Flagan, R. C., and Seinfeld, J. H.: Secondary organic aerosol from the photooxidation of aromatic hydrocarbons: Molecular composition, Environ. Sci. Technol., 31, 1345-1358, 1997.

Fowlis, I. A.: Gas Chromatography, 2, Analytical Chemistry by Open Learning, John Wiley and Sons, 1995.

Gao, S., Keywood, M., Ng, N. L., Surratt, J., Varutbangkul, V., Bahreini, R., Flagan, R. C., and Seinfeld, J. H.: Low-molecularweight and oligomeric components in secondary organic aerosol from the ozonolysis of cycloalkenes and alpha-pinene, J. Phys. Chem. A, 108, 10 147-10 164, 2004a.

Gao, S., Ng, N. L., Keywood, M., Varutbangkul, V., Bahreini, R., Nenes, A., He, J. W., Yoo, K. Y., Beauchamp, J. L., Hodyss, R. P., Flagan, R. C., and Seinfeld, J. H.: Particle phase acidity and oligomer formation in secondary organic aerosol, Environ. Sci. Technol., 38, 6582-6589, 2004b.

Hamilton, J. F., Webb, P. J., Lewis, A. C., Hopkins, J. R., Smith, S., and Davy, P.: Partially oxidised organic components in urban 
aerosol using GCXGC-TOF/MS, Atmos. Chem. Phys., 4, 12791290, 2004,

http://www.atmos-chem-phys.net/4/1279/2004/.

Hamilton, J. F., Webb, P. J., Lewis, A. C., and Reviejo, M. M.: Quantifying small molecules in secondary organic aerosol formed during the photo-oxidation of toluene with hydroxyl radicals, Atmos. Environ., 39, 7263-7275, 2005.

Hastings, W. P., Koehler, C. A., Bailey, E. L., and De Haan, D. O.: Secondary organic aerosol formation by glyoxal hydration and oligomer formation: Humidity effects and equilibrium shifts during analysis, Environ. Sci. Technol., 39, 8728-8735, 2005.

Jang, M. S. and Kamens, R. M.: Characterization of secondary aerosol from the photooxidation of toluene in the presence of $\mathrm{NO}_{\mathrm{x}}$ and 1-propene, Environ. Sci. Technol., 35, 3626-3639, 2001.

Kalberer, M., Paulsen, D., Sax, M., Steinbacher, M., Dommen, J., Prevot, A. S. H., Fisseha, R., Weingartner, E., Frankevich, V., Zenobi, R., and Baltensperger, U.: Identification of polymers as major components of atmospheric organic aerosols, Science, 303, 1659-1662, 2004.

Kalberer, M., Sax, M., and Samburova, V.: Characterization of polymers in nanometer sized atmospheric aerosol particles, Chimia, 59, 43-43, 2005.

Kalberer, M., Yu, J., Cocker, D. R., Flagan, R. C., and Seinfeld, J. H.: Aerosol formation in the cyclohexene-ozone system, Environ. Sci. Technol., 34, 4894-4901, 2000.

Kimura, M., Hasegawa, Y., Nakagawa, K., Kajita, M., Watanabe, K., and Yamaguchi, S.: A sensitive method for 4-hydroxybutyric acid in urine using gas chromatography-mass spectrometry, J. Chromat. B, 792, 141-144, 2003.

Martin-Reviejo, M. and Wirtz, K.: Is benzene a precursor for secondary organic aerosol?, Environ. Sci. Technol., 39, 1045-1054, 2005.

Putaud, J. P., Raes, F., Van Dingenen, R., Bruggemann, E., Facchini, M. C., Decesari, S., Fuzzi, S., Gehrig, R., Huglin, C., Laj, P., Lorbeer, G., Maenhaut, W., Mihalopoulos, N., Mulller, K., Querol, X., Rodriguez, S., Schneider, J., Spindler, G., ten Brink, H., Torseth, K., and Wiedensohler, A.: European aerosol phenomenology-2: chemical characteristics of particulate matter at kerbside, urban, rural and background sites in Europe, Atmos. Environ., 38, 2579-2595, 2004.
Saxena, P. and Hildemann, L. M.: Water-soluble organics in atmospheric particles: A critical review of the literature and application of thermodynamics to identify candidate compounds, J. Atmos. Chem., 24, 57-109, 1996.

Surratt, J. D., Murphy, S. M., Kroll, J. H., Ng, N. L., Hildebrandt, L., Sorooshian, A., Szmigielski, R., Vermeylen, R., Maenhaut, W., Claeys, M., Flagan, R. C., and Seinfeld, J. H.: Chemical composition of secondary organic aerosol formed from the photooxidation of isoprene, J. Phys. Chem. A, 110, 9665-9690, 2006.

Talbot, R. W., Andreae, M. O., Andreae, T. W., and Harriss, R. C.: Regional Aerosol Chemistry of the Amazon Basin During the Dry Season, J. Geophys. Res., 93, 1499-1508, 1988.

Tolocka, M. P., Jang, M., Ginter, J. M., Cox, F. J., Kamens, R. M., and Johnston, M. V.: Formation of oligomers in secondary organic aerosol, Environ. Sci. Technol., 38, 1428-1434, 2004.

Zahardis, J., LaFranchi, B. W., and Petrucci, G. A.: Direct observation of polymerization in the oleic acid-ozone heterogeneous reaction system by photoelectron resonance capture ionization aerosol mass spectrometry, Atmos. Environ., 40, 1661-1670, 2006.

Ziemann, P. J.: Evidence for low-volatility diacyl peroxides as a nucleating agent and major component of aerosol formed from reactions of $\mathrm{O}-3$ with cyclohexene and homologous compounds, J. Phys. Chem. A, 106, 4390-4402, 2002.

Ziemann, P. J.: Formation of alkoxyhydroperoxy aldehydes and cyclic peroxyhemiacetals from reactions of cyclic alkenes with O-3 in the presence of alcohols, J. Phys. Chem. A, 107, 20482060, 2003.

Ziemann, P. J.: Aerosol products, mechanisms, and kinetics of heterogeneous reactions of ozone with oleic acid in pure and mixed particles, Faraday Discuss., 130, 469-490, 2005. 